\title{
CAPÍTULO 51: BACTÉRIAS ÁCIDO LÁCTICAS NA DESCONTAMINAÇÃO DE AFLATOXINAS EM LEITE BOVINO: UMA REVISÃO
}

\section{CHAPTER 51: LACTIC ACID BACTERIA IN THE DECONTAMINATION OF AFLATOXINS IN BOVINE MILK: A REVIEW}

\author{
Rosana Basso Kraus ${ }^{1}$; Pedro Rassier dos Santos ${ }^{2}$; Giniani Carla Dors ${ }^{3}$; Patrícia da Silva Nascente ${ }^{4}$; Rafael \\ Guerra Lund ${ }^{5}$
}

\begin{abstract}
Resumo
As aflatoxinas são compostos químicos tóxicos produzidos por fungos do gênero Aspergillus que podem contaminar grãos e cereais, base para rações utilizadas em bovinos. A aflatoxina $\mathrm{M}_{1}$, derivada da hidroxilação da aflatoxina $\mathrm{B}_{1}$, é encontrada no leite, mas a aflatoxina $\mathrm{B}_{1}$ também tem sido relatada e precisa ser avaliada, pois é mais tóxica que a aflatoxina $\mathbf{M}_{1}$. Assim, o objetivo deste trabalho foi revisar o efeito do uso de bactérias ácido láticas na descontaminação de aflatoxinas $\mathrm{B}_{1}$ e $\mathrm{M}_{1}$ presentes no leite e derivados lácteos. A aplicação de bactérias ácido láticas em ensaios de descontaminação de aflatoxinas tem sido promissor. Entretanto, a redução dos níveis de aflatoxinas presente no alimento depende da bactéria que será utilizada, bem como sua concentração, meio onde será realizado o ensaio, nível de contaminação inicial, tempo de contato entre micro-organismo e a aflatoxina, e a estabilidade desta ligação.
\end{abstract}

Palavras-Chave: aflatoxinas $\mathrm{B}_{1}$ e $\mathrm{M}_{1}$, descontaminação, leite, processamento de alimentos.

\begin{abstract}
Aflatoxins are toxic chemical compounds produced by fungi of the Aspergillus genus that can contaminate graisn and cereals, the basis for feed used in cattle. Aflatoxin $\mathrm{M}_{1}$, derived from the hydroxylation of aflatoxin $\mathrm{B}_{1}$, is found in milk, but aflatoxin $\mathrm{B}_{1}$ has also been reported and needs to be evaluated, as it is more toxic than aflatoxin $\mathrm{M}_{1}$. Thus, the objective of this study was to review the effect of the use of lactic acid bacteria in the decontamination of aflatoxins $\mathrm{B}_{1}$ and $\mathrm{M}_{1}$ present in milk and dairy products. The application of lactic acid bacteria in aflatoxin decontamination trials has been promising. However, the reduction in the levels of aflatoxins present in the food depends on the bacteria that will be used, as well as its concentration, medium where the test will be performed, initial contamination level, contact time between microorganism and aflatoxin, and the stability of this link.
\end{abstract}

Keywords: aflatoxins $\mathrm{B}_{1}$ and $\mathrm{M}_{1}$, milk, decontamination, food processing.

\footnotetext{
${ }^{1}$ Programa de Pós-Graduação em Bioquímica e Bioprospecção (PPGBBio), Universidade Federal de Pelotas, rosana_basso_kraus@hotmail.com

${ }^{2}$ Programa de Pós-Graduação em Microbiologia e Parasitologia (PPGMP), Universidade Federal de Pelotas, rassier1907@gmail.com

${ }^{3}$ Mestrado Profissional em Ciência e Tecnologia de Alimentos, Universidade Federal de Pelotas, Dr ${ }^{\mathrm{a}}$ em Engenharia e Ciência de Alimentos, dorsgi@yahoo.com.br

${ }^{4}$ PPGMP, Universidade Federal de Pelotas, pattsn@gmail.com

${ }^{5}$ PPGBBio, Universidade Federal de Pelotas, rafael.lund@ gmail.com
} 


\section{Introdução}

As micotoxinas são substâncias resultantes do metabolismo secundário de algumas espécies fúngicas, principalmente Aspergillus, Fusarium e Penicillium (SWEENEY; DOBSON, 1998) e podem acometer diversas culturas agrícolas antes e/ou após a colheita, durante a secagem ou armazenamento (PITT; TANIWAKI; COLE, 2013). Dentre as micotoxinas de maior ocorrência nos alimentos destacam-se as aflatoxinas (AFLA), produzidas por fungos do gênero Aspergillus, principalmente A. flavus, A. parasiticus e A. nomius (PRANDINI et al., 2009), classificando-se em B (AFLAB 1 e AFLAB ${ }_{2}$ ) e G (AFLAG 1 e $\left.\mathrm{AFLAG}_{2}\right)(\mathrm{CREPPY}, 2002)$.

$\mathrm{O}$ consumo de alimentos contaminados por $\mathrm{AFLAB}_{1}$ pelos animais resulta na conversão de 0,3 a 6,2\% em AFLAM 1 , ou seja, ocorre a hidroxilação e os metabólitos hidroxilados são convertidos em $\mathrm{AFLAM}_{1}$ sendo liberados através da urina e/ou leite (CREPPY, 2002). A presença destes contaminantes no leite afeta a segurança do alimento, pois são compostos cancerígenos e mutagênicos, representando um problema de saúde publica, (BENKERROUM, 2019; WHO, 2018). Consequentemente, inúmeros países elaboraram Limites Máximos Tolerados (LMT) destas micotoxinas em alimentos.

A partir destas considerações fica evidente a necessidade de buscar alternativas que minimizem a ocorrência deste perigo na obtenção do leite, pois as aflatoxinas são estáveis aos métodos de processamento (IHA et al., 2013). Este estudo tem por objetivo revisar o efeito do uso de bactérias ácido-láticas na descontaminação de aflatoxinas $\mathrm{B}_{1}$ e $\mathrm{M}_{1}$ presentes no leite e derivados lácteos.

\section{Desenvolvimento}

\section{Aflatoxinas em Leite e Produtos Lácteos}

O leite de boa qualidade deve apresentar baixos níveis de células somáticas e bactérias totais, ausência de micro-organismos patogênicos ou resíduos químicos como, por exemplo, antibióticos (BRASIL, 2018, 2018a). Além disso, a composição do leite cru ou pasteurizado deve ter teores mínimos de proteína, gordura e extrato seco desengordurado, os quais variam de acordo com o tipo de leite que será produzido (BRASIL, 2018) e em razão da raça do animal e do manejo (SOUZA; CARVALHO; MENDONÇA, 2010).

Além das legislações exigidas com relação à qualidade do leite, há a Resolução número 7, publicada em 18 de fevereiro de 2011, que estabelece o limite para $\mathrm{AFLAM}_{1}$ para leite líquido $\left(0,5 \mu \mathrm{g} \mathrm{kg}^{-1}\right)$, leite em pó $\left(5,0 \mu \mathrm{g} \mathrm{kg}^{-1}\right)$ e queijos $\left(2,5 \mu \mathrm{g} \mathrm{kg}^{-1}\right)$ (ANVISA, 2011). Embora alguns trabalhos relatem a presença de $\mathrm{AFLAB}_{1}$ no leite (GONÇALVES et al., 2018; 
SIBAJA et al., 2019; BECKER-ALGERI et al., 2020) a legislação só apresenta LMT para $\mathrm{AFLAM}_{1}$. A legislação de alimentos para consumo animal preconiza que qualquer matériaprima a ser utilizada diretamente ou como ingrediente para rações destinadas ao consumo animal não ultrapasse $50 \mu \mathrm{g} \mathrm{kg}^{-1}$ da somatória de AFLAs (BRASIL, 1988). As principais legislações internacionais para leite e produtos derivados, bem como de matérias-primas para consumo animal são da Comissão da Regulamentação da União Europeia (CRUE) e da Food and Drug Administration (FDA) (COMISSÃO DA UNIÃO EUROPEIA, 2020; FOOD AND DRUG ADMINISTRATION, 2020).

As AFLAs têm como característica uma estrutura policíclica derivada de um núcleo cumarina juntamente com um sistema bifurano e uma pentanona (AFLAB) ou lactona (AFLAG) (BENNETT; KLICH, 2003). A International Agency for Research on Cancer (IARC) (1993) considera a $\mathrm{AFLAB}_{1}$ um carcinógeno humano do grupo 1 , enquanto a $\mathrm{AFLAM}_{1}$ é um provável carcinógeno humano, pertencendo ao grupo $2 \mathrm{~B}$, em virtude da toxicidade da $\mathrm{AFLAB}_{1}$ ser maior, quando comparada com a $\mathrm{AFLAM}_{1}$ (CREPPY, 2002). As AFLAs têm efeito carcinogênico, teratogênico, hepatotóxico, imunossupressor, atingindo principalmente o fígado e, dependendo do nível de exposição, essa toxicidade pode ser aguda ou crônica (BENNET; KLICH, 2003). Além da toxicidade, são compostos altamente estáveis aos métodos de processamento como esterilização comercial, pasteurização ou fervura (AWASTHI et al., 2012; BAKIRCI, 2001; FERNANDES et al., 2012; GOVARIS et al., 2002; IHA et al., 2013).

A ocorrência de AFLAs têm sido relatada em grãos, rações e silagem de grãos (MOSS, 1998; O’BRIEN et al., 2005; SASSAHARA; NETTO; YANAKA, 2005; OMEIZA et al.,2018; DADZIE et al., 2019), sendo preocupante, uma vez que o sistema digestivo dos animais não é suficiente para degradar essas toxinas (OBREMSKI et al., 2009). A metabolização da $\mathrm{AFLAB}_{1}$ ocorre no fígado, através de um conjunto de enzimas do citocromo $\mathrm{P}_{450}$, que são consideradas hemoproteínas e têm como função a conversão desses compostos xenobióticos em moléculas mais hidrossolúveis (KLEIN et al., 2000; PEI et al., 2009). O principal metabólito formado é $\mathrm{AFLAB}_{1}-8,9$ epóxido, responsável pelos efeitos tóxicos agudos, mutagênicos e carcinogênicos e a AFLAM 1 (MURPHY et al., 2006).

A ocorrência das AFLAs é um problema mundial, e de acordo com estudo elaborado por Becker-Algeri et al. (2016), a partir de dados coletados até 2015, foi possível verificar que a incidência de $\mathrm{AFLAM}_{1}$ em leite e derivados lácteos é relativamente mais baixa nos países europeus (Portugal, Turquia, Itália e Croácia), independentemente do tipo de amostra. No Brasil, devido à sua extensão, diferenças de clima e produção de leite e latícinios, os 
KRAUS, R. B; SANTOS, P. R; DORS, G. C; NASCENTE, P. S; LUND, R. G.

resultados da frequência variam conforme a porcentagem de ocorrência da micotoxina $(30,7 \%$ a 100\%) e sobre os níveis de contaminação encontrados $\left(0,0018\right.$ a $\left.4,1 \mu \mathrm{g} \mathrm{L}^{-1}\right)$.

Além dos efeitos tóxicos das AFLAs, a estabilidade durante o processamento é outra problemática que vem sendo avaliada, assim como a transferência e a distribuição destas toxinas nos derivados lácteos (ALAHLAH et al., 2020; DEVECI, 2007; HASSANIN, 1994; LÓPEZ et al., 2001; SCAGLIONI et al., 2014; TADESSE; BERHANU; WOLDEGIORGIS, 2020). O Quadro 1 apresenta dados de ocorrência de AFLAM $_{1}$ e AFLAB 1 em leite e produtos lácteos nos últimos cinco anos.

Quadro 1. Frequência e ocorrência de aflatoxinas em leite e derivados lácteos relatadas na literatura.

\begin{tabular}{|c|c|c|c|c|}
\hline $\begin{array}{l}\text { País I } \\
\text { Autores }\end{array}$ & Amostra & $\begin{array}{l}\text { Frequência } \\
(\%)\end{array}$ & Mín - Máx & AFLAs \\
\hline \multirow{2}{*}{$\begin{array}{l}\text { Costa } \\
\text { Rica / } \\
\text { Chavarría } \\
\text { et al., } \\
2015\end{array}$} & Leite & $\begin{array}{l}(3 / 70) 4,3 \\
(22 / 70) 31,4 \\
(44 / 70) 62,8 \\
(1 / 70) 1,4 \\
\end{array}$ & $\begin{array}{l}<14 \mathrm{ng} \mathrm{L}^{-1} \\
20-50 \mathrm{ng} \mathrm{L}^{-1} \\
50-500 \mathrm{ng} \mathrm{L}^{-1} \\
>500 \mathrm{ng} \mathrm{L}^{-1}\end{array}$ & \multirow{2}{*}{$\mathrm{M}_{1}$} \\
\hline & Queijo & $\begin{array}{l}(44 / 70) 62,8 \\
(13 / 70) 18,6 \\
(13 / 70) 18,6) \\
\end{array}$ & $\begin{array}{l}<23 \mathrm{ng} \mathrm{kg}^{-1} \\
20-50 \mathrm{ng} \mathrm{kg}^{-1} \\
50-500 \mathrm{ng} \mathrm{kg}^{-1}\end{array}$ & \\
\hline $\begin{array}{l}\text { Brasil / } \\
\text { Sartori et } \\
\text { al., } 2015^{*}\end{array}$ & $\begin{array}{l}\text { Leite UHT } \\
\text { Leite em pó }\end{array}$ & $\begin{array}{l}(11 / 16) 69 \\
(53 / 72) 74\end{array}$ & $\begin{array}{l}0,005-0,042 \mu \mathrm{g} \mathrm{kg}^{-1} \\
0,08-1,19 \mu \mathrm{g} \mathrm{kg}^{-1}\end{array}$ & $\mathrm{M}_{1}$ \\
\hline \multirow[t]{7}{*}{$\begin{array}{l}\text { Sérvia / } \\
\text { Tomaševi } \\
\text { ć et al., } \\
2015\end{array}$} & Leite cru & $\begin{array}{l}(138 / 678) 20,3 \\
(158 / 678) 23,3 \\
(215 / 678) 31,7 \\
(118 / 678) 17,4 \\
(49 / 678) 7,2 \\
\end{array}$ & $\begin{array}{l}\leq 0,025 \mu \mathrm{g} \mathrm{kg}^{-1} \\
0,026-0,05 \mu \mathrm{g} \mathrm{kg}^{-1} \\
0,051-0,5 \mu \mathrm{g} \mathrm{kg}^{-1} \\
0,51-1,0 \mu \mathrm{g} \mathrm{kg}^{-1} \\
>1,0 \mu \mathrm{g} \mathrm{kg}^{-1}\end{array}$ & \multirow{7}{*}{$\mathrm{M}_{1}$} \\
\hline & Leite tratado termicamente & $\begin{array}{l}(121 / 438) 27,6 \\
(174 / 438) 39,7 \\
(131 / 438) 29,9 \\
(12 / 438) 2,7\end{array}$ & $\begin{array}{l}\leq 0,025 \mu \mathrm{g} \mathrm{kg}^{-1} \\
0,026-0,05 \mu \mathrm{g} \mathrm{kg}^{-1} \\
0,051-0,5 \mu \mathrm{g} \mathrm{kg}^{-1} \\
0,51-1,0 \mu \mathrm{g} \mathrm{kg}^{-1}\end{array}$ & \\
\hline & Leite em pó & $\begin{array}{l}(45 / 67) 67,1 \\
(5 / 67) 7,4 \\
(5 / 67) 7,4 \\
(1 / 67) 1,4 \\
(11 / 67) 16,4\end{array}$ & $\begin{array}{l}\leq 0,025 \mu \mathrm{g} \mathrm{kg}^{-1} \\
0,026-0,05 \mu \mathrm{g} \mathrm{kg}^{-1} \\
0,051-0,5 \mu \mathrm{g} \mathrm{kg}^{-1} \\
0,51-1,0 \mu \mathrm{g} \mathrm{kg}^{-1} \\
>1,0 \mu \mathrm{g} \mathrm{kg}^{-1}\end{array}$ & \\
\hline & Iogurte & $\begin{array}{l}(14 / 56) 25,0 \\
(20 / 56) 35,7 \\
(22 / 56) 39,2\end{array}$ & $\begin{array}{l}\leq 0,025 \mu \mathrm{g} \mathrm{kg}^{-1} \\
0,026-0,05 \mu \mathrm{g} \mathrm{kg}^{-1} \\
0,051-0,5 \mu \mathrm{g} \mathrm{kg}^{-1}\end{array}$ & \\
\hline & Sorvete & $\begin{array}{l}(7 / 21) 33,3 \\
(3 / 21) 14,2 \\
(11 / 21) 52,3 \\
\end{array}$ & $\begin{array}{l}\leq 0,025 \mu \mathrm{g} \mathrm{kg}^{-1} \\
0,026-0,05 \mu \mathrm{g} \mathrm{kg}^{-1} \\
0,051-0,5 \mu \mathrm{g} \mathrm{kg}^{-1}\end{array}$ & \\
\hline & Fórmula láctea infantil & $\begin{array}{l}(31 / 33) 93,9 \\
(2 / 33) 6,0\end{array}$ & $\begin{array}{l}\leq 0,025 \mu \mathrm{g} \mathrm{kg}^{-1} \\
0,026-0,05 \mu \mathrm{g} \mathrm{kg}^{-1}\end{array}$ & \\
\hline & Queijo branco & $(8 / 47) 17,0$ & $\leq 0,025 \mu \mathrm{g} \mathrm{kg}^{-1}$ & \\
\hline
\end{tabular}




\begin{tabular}{|c|c|c|c|c|}
\hline & & $\begin{array}{l}(11 / 47) 23,4 \\
(26 / 47) 55,3 \\
(2 / 47) 4,2\end{array}$ & $\begin{array}{l}0,026-0,05 \mu \mathrm{g} \mathrm{kg}^{-1} \\
0,051-0,5 \mu \mathrm{g} \mathrm{kg}^{-1} \\
0,51-1,0 \mu \mathrm{g} \mathrm{kg}^{-1}\end{array}$ & \\
\hline & Queijo duro & $\begin{array}{l}(6 / 27) 22,2 \\
(5 / 27) 18,5 \\
(8 / 27) 29,6 \\
(2 / 27) 7,4 \\
(6 / 27) 22,2\end{array}$ & $\begin{array}{l}\leq 0,025 \mu \mathrm{g} \mathrm{kg}^{-1} \\
0,026-0,05 \mu \mathrm{g} \mathrm{kg}^{-1} \\
0,051-0,5 \mu \mathrm{g} \mathrm{kg}^{-1} \\
0,51-1,0 \mu \mathrm{g} \mathrm{kg}^{-1} \\
>1,0 \mu \mathrm{g} / \mathrm{kg}\end{array}$ & \\
\hline & Outros lácteos & $\begin{array}{l}(27 / 71) 38,0 \\
(16 / 71) 22,5 \\
(27 / 71) 38,0 \\
(1 / 71) 1,4\end{array}$ & $\begin{array}{l}\leq 0,025 \mu \mathrm{g} \mathrm{kg}^{-1} \\
0,026-0,05 \mu \mathrm{g} \mathrm{kg}^{-1} \\
0,051-0,5 \mu \mathrm{g} \mathrm{kg}^{-1} \\
0,51-1,0 \mu \mathrm{g} \mathrm{kg}^{-1}\end{array}$ & \\
\hline \multirow{3}{*}{$\begin{array}{l}\text { Irã / } \\
\text { Bahrami; } \\
\text { Shahbazi; } \\
\text { Nikousefa } \\
\text { t, 2016* }\end{array}$} & Leite cru bovino & $(54 / 64) 84,3$ & $6,1-188,2 \mathrm{ng} \mathrm{L}^{-1}$ & \multirow[b]{3}{*}{$\mathrm{M}_{1}$} \\
\hline & Queijo & $(25 / 40) 65,5$ & $52,5-272 \mathrm{ng} \mathrm{kg}^{-1}$ & \\
\hline & Iogurte & $(10 / 42) 23,8$ & $6,3-21,3 \mathrm{ng} \mathrm{kg}^{-1}$ & \\
\hline $\begin{array}{l}\text { Brasil / } \\
\text { Gonçalves } \\
\text { et al., } \\
2017\end{array}$ & Leite fresco & $\begin{array}{l}(24 / 52) 46,2 \\
(4 / 52) 7,7 \\
(3 / 52) 5,6 \\
(19 / 52) 36,5 \\
(2 / 52) 3,8 \\
\end{array}$ & $\begin{array}{l}\leq 0,09 \mu \mathrm{g} \mathrm{L}^{-1} \\
0,1-0,25 \mu \mathrm{g} \mathrm{L}^{-1} \\
0,26-0,49 \mu \mathrm{g} \mathrm{L}^{-1} \\
\geq 0,50 \mu \mathrm{g} \mathrm{L}^{-1} \\
>1,00 \mu \mathrm{g} \mathrm{L}^{-1}\end{array}$ & $\mathrm{M}_{1}$ \\
\hline \multirow{12}{*}{$\begin{array}{l}\text { Paquistão } \\
\text { / Iqbal; } \\
\text { Asi; } \\
\text { Malik, } \\
2017^{*}\end{array}$} & Leite cru (verão) & $(19 / 32) 59,4$ & $0,4-229,6 \mathrm{ng} \mathrm{L}^{-1}$ & \multirow{12}{*}{$\mathrm{M}_{1}$} \\
\hline & Leite UHT (verão) & $(16 / 25) 64,0$ & $0,4-190,8 \mathrm{ng} \mathrm{L}^{-1}$ & \\
\hline & Leite em pó (verão) & $(9 / 32) 28,1$ & $0,4-178,5 \mathrm{ng} \mathrm{L}^{-1}$ & \\
\hline & Leite com sabor (verão) & $(12 / 25) 48,0$ & $0,4-110,1 \mathrm{ng} \mathrm{L}^{-1}$ & \\
\hline & Iogurte (verão) & $(11 / 30) 36,6$ & $0,4-158,2 \mathrm{ng} \mathrm{L}^{-1}$ & \\
\hline & Iogurte com sabor (verão) & $(10 / 25) 40,0$ & $0,4-102,5 \mathrm{ng} \mathrm{L}^{-1}$ & \\
\hline & Leite cru (inverno) & $\begin{array}{l}(29 / 42) 69 \\
69\end{array}$ & $0,4-345,8 \mathrm{ng} \mathrm{L}^{-1}$ & \\
\hline & Leite UHT (inverno) & $(26 / 35) 74,2$ & $0,4-302,9 \mathrm{ng} \mathrm{L}^{-1}$ & \\
\hline & Leite em pó (inverno) & $(12 / 32) 37,5$ & $0,4-278,4 \mathrm{ng} \mathrm{L}^{-1}$ & \\
\hline & Leite com sabor (inverno) & $(15 / 28) 53,6$ & $0,4-198,3 \mathrm{ng} \mathrm{L}^{-1}$ & \\
\hline & Iogurte (inverno) & $(15 / 36) 41,6$ & $0,4-196,3 \mathrm{ng} \mathrm{L}^{-1}$ & \\
\hline & Iogurte com sabor (inverno) & $\begin{array}{l}(17 / 30) 56,6 \\
\end{array}$ & $0,4-220,5 \mathrm{ng} \mathrm{L}^{-1}$ & \\
\hline \multirow{8}{*}{$\begin{array}{l}\text { Brasil / } \\
\text { Gonçalves } \\
\text { et al., } \\
2018^{*}\end{array}$} & Leite integral & $(19 / 26) 73,1$ & $60-3670 / 40-150 \mathrm{ng} \mathrm{L}^{-1}$ & \multirow{8}{*}{$\mathrm{M}_{1} / \mathrm{B}_{1}$} \\
\hline & Leite desnatado & $(7 / 11) 63,6$ & $40-1050 / 40-600 \mathrm{ng} \mathrm{L}^{-1}$ & \\
\hline & Leite semidesnatado & $(9 / 12) 75$ & $90-1400 /-\mathrm{ng} \mathrm{L}^{-1}$ & \\
\hline & Leite em pó integral & $(6 / 10) 60$ & $88-2800 /-\operatorname{ng~L}^{-1}$ & \\
\hline & Leite em pó infantil & $(0 / 3) 0$ & $-/-\mathrm{ng} \mathrm{kg}^{-1}$ & \\
\hline & $\overline{\text { Leite em pó integral - marca I }}$ & $(10 / 17) 58,8$ & $32-724 /-\mathrm{ng} \mathrm{kg}^{-1}$ & \\
\hline & Leite em pó integral - marca II & $(11 / 16) 68,7$ & $213-2216 /-\mathrm{ng} \mathrm{kg}^{-1}$ & \\
\hline & $\begin{array}{l}\text { Leite em pó integral - marca } \\
\text { III }\end{array}$ & $\begin{array}{l}(17 / 17) 100 \\
100\end{array}$ & $1280-2896 /-\mathrm{ng} \mathrm{kg}^{-1}$ & \\
\hline \multirow[t]{2}{*}{$\begin{array}{l}\text { Turquia / } \\
\text { Sakin et } \\
\text { al., } 2018\end{array}$} & Queijo Sürk & $\begin{array}{l}(1 / 30) 3,3 \\
(13 / 30) 43,3 \\
(9 / 30) 30 \\
(3 / 30) 10 \\
(2 / 30) 6,7 \\
(2 / 30) 6,7\end{array}$ & $\begin{array}{l}<0,035 \mu \mathrm{g} \mathrm{kg}^{-1} \\
<0,1 \mu \mathrm{g} \mathrm{kg}^{-1} \\
0,1-0,25 \mu \mathrm{g} \mathrm{kg}^{-1} \\
0,25-0,5 \mu \mathrm{g} \mathrm{kg}^{-1} \\
0,5-2 \mu \mathrm{g} \mathrm{kg}^{-1} \\
2-5 \mu \mathrm{g} \mathrm{kg}^{-1}\end{array}$ & $\begin{array}{l}\mathrm{B}_{1} \\
\mathrm{~B}_{1} \\
\mathrm{~B}_{1} \\
\mathrm{~B}_{1} \\
\mathrm{~B}_{1} \\
\mathrm{~B}_{1}\end{array}$ \\
\hline & & $\begin{array}{l}(26 / 30) 86,7 \\
\end{array}$ & $<0,059 \mu \mathrm{g} \mathrm{kg}^{-1}$ & $\mathrm{~B}_{2}$ \\
\hline
\end{tabular}




\begin{tabular}{|c|c|c|c|c|}
\hline & & $(4 / 30) 13,3$ & $<0,17 \mu \mathrm{g} \mathrm{kg}^{-1}$ & $\overline{\mathrm{B}_{2}}$ \\
\hline & & $\begin{array}{l}(25 / 30) 83,3 \\
(3 / 30) 10 \\
(2 / 30) 6,7\end{array}$ & $\begin{array}{l}<0,053 \mu \mathrm{g} \mathrm{kg}^{-1} \\
<0,14 \mu \mathrm{g} \mathrm{kg}^{-1} \\
0,14-0,25 \mu \mathrm{kg}^{-1}\end{array}$ & $\begin{array}{l}\mathrm{G}_{1} \\
\mathrm{G}_{1} \\
\mathrm{G}_{1}\end{array}$ \\
\hline & & $\begin{array}{l}(5 / 30) 16,7 \\
(6 / 30) 20 \\
(6 / 30) 20 \\
(8 / 30) 26,6 \\
(5 / 30) 16,7 \\
\end{array}$ & $\begin{array}{l}<0,061 \mu \mathrm{g} \mathrm{kg}^{-1} \\
<0,16 \mu \mathrm{g} \mathrm{kg}^{-1} \\
0,16-0,25 \mu \mathrm{g} \mathrm{kg}^{-1} \\
0,25-0,5 \mu \mathrm{g} \mathrm{kg}^{-1} \\
0,5-2 \mu \mathrm{g} \mathrm{kg}^{-1}\end{array}$ & $\begin{array}{l}\mathrm{G}_{2} \\
\mathrm{G}_{2} \\
\mathrm{G}_{2} \\
\mathrm{G}_{2} \\
\mathrm{G}_{2}\end{array}$ \\
\hline & & $\begin{array}{l}(5 / 30) 16,7 \\
(9 / 30) 30 \\
(13 / / 30) 43,3 \\
(3 / 30) 10\end{array}$ & $\begin{array}{l}<0,033 \mu \mathrm{g} \mathrm{kg}^{-1} \\
<0,07 \mu \mathrm{g} \mathrm{kg}^{-1} \\
0,07-0,25 \mu \mathrm{g} \mathrm{kg}^{-1} \\
0,25-0,5 \mu \mathrm{g} \mathrm{kg}^{-1}\end{array}$ & $\begin{array}{l}\mathrm{M}_{1} \\
\mathrm{M}_{1} \\
\mathrm{M}_{1} \\
\mathrm{M}_{1}\end{array}$ \\
\hline \multirow[t]{2}{*}{$\begin{array}{l}\text { China / } \\
\text { Xiong et } \\
\text { al., } 2018^{*}\end{array}$} & Leite pasteurizado & $\begin{array}{l}(11 / 131) 8,4 \\
(42 / 131) 32,1 \\
(23 / 131) 17,5 \\
(12 / 131) 9,2 \\
(43 / 131) 32,8 \\
\end{array}$ & $\begin{array}{l}<5 \mathrm{ng} \mathrm{L}^{-1} \\
5-49,9 \mathrm{ng} \mathrm{L}^{-1} \\
50-99,5 \mathrm{ng} \mathrm{L}^{-1} \\
100-199,9 \mathrm{ng} \mathrm{L}^{-1} \\
>200 \mathrm{ng} \mathrm{L}^{-1}\end{array}$ & \multirow[t]{2}{*}{$\mathrm{M}_{1}$} \\
\hline & Leite UHT & $\begin{array}{l}53 / 111) 47,7 \\
(56 / 111) 50,5 \\
(2 / 111) 1,8\end{array}$ & $\begin{array}{l}5 \mathrm{ng} \mathrm{L}^{-1} \\
5-49,9 \mathrm{ng} \mathrm{L}^{-1} \\
50-99,5 \mathrm{ng} \mathrm{L}^{-1}\end{array}$ & \\
\hline \multirow{4}{*}{$\begin{array}{l}\text { Brasil / } \\
\text { Sibaja et } \\
\text { al., } 2019^{*}\end{array}$} & Leite em pó integral & $(30 / 30) 100$ & $0,35-1,19 \mu \mathrm{g} \mathrm{kg}^{-1}$ & \multirow{4}{*}{$\mathrm{M}_{1}$} \\
\hline & Leite em pó desnatado & $(6 / 6 /) 100$ & $0,46-1,03 \mu \mathrm{g} \mathrm{kg}^{-1}$ & \\
\hline & $\begin{array}{l}\begin{array}{l}\text { Leite em pó sem lactose } \\
\text { semidesnatado }\end{array} \\
\end{array}$ & $(9 / 9) 100$ & $0,33-1,18 \mu \mathrm{g} \mathrm{kg}^{-1}$ & \\
\hline & $\overline{\text { Leite infantil em pó }}$ & $(6 / 6) 100$ & $0,20-0,34 \mu \mathrm{g} \mathrm{kg}^{-1}$ & \\
\hline \multirow{10}{*}{$\begin{array}{l}\text { Brasil / } \\
\text { Becker- } \\
\text { Algeri et } \\
\text { al., } 2020\end{array}$} & Leite integral UHT - PR & $(35 / 93) 37,6$ & $0,53-4,62 /-\mu \mathrm{g} \mathrm{L}^{-1}$ & \multirow{10}{*}{$\mathrm{M}_{1} / \mathrm{B}_{1}$} \\
\hline & Leite integral UHT - SC & (35/93) 37,6 & $\overline{0,34-0,93 / 1,39-1,62 \mu \mathrm{g}}$ & \\
\hline & Leite integral UHT - RS & (23/93) 24,7 & & \\
\hline & Leite semidesnatado - PR & $\begin{array}{l}(24 / 61) 39,3 \\
\end{array}$ & $-/-\mu \mathrm{gL}^{-1}$ & \\
\hline & Leite semidesnatado - SC & (23/61) 37,7 & $0,30-0,48 /-\mu \mathrm{g} \mathrm{L}-1$ & \\
\hline & Leite semidesnatado - RS & $(14 / 61) 22,9$ & $\overline{0,33-0,51 / 1,69-8,8 \mu \mathrm{g}}$ & \\
\hline & Leite desnatado - PR & $(30 / 74) 40,5$ & $\mathrm{~L}^{-1}$ & \\
\hline & Leite desnatado - SC & (24/74) 32,4 & $-/-\mu g \mathrm{~L}^{-1}$ & \\
\hline & Leite desnatado - RS & (20/74) 27,0 & $0,32-0,54 /-\mu \mathrm{g} \mathrm{L}^{-1}$ & \\
\hline & & & $\frac{0,34-0,42 /-\mu \mathrm{g} \mathrm{L}^{-1}}{-/-\mu \mathrm{g} \mathrm{L}^{-1}}$ & \\
\hline \multirow[t]{4}{*}{\begin{tabular}{|lr} 
Líbano & $/$ \\
Daou & et \\
al., $2020^{*}$
\end{tabular}} & Leite cru & $\begin{array}{l}(289 / 701) 41,2 \\
(123 / 701) 17,5 \\
(93 / 701) 13,3 \\
(196 / 701) 28 \\
\end{array}$ & $\begin{array}{l}<0,011 \mu \mathrm{g} \mathrm{L}^{-1} \\
0,011-0,024 \mu \mathrm{g} \mathrm{L}^{-1} \\
0,025-0,05 \mu \mathrm{g} \mathrm{L}^{-1} \\
>0,05 \mu \mathrm{g} \mathrm{L}^{-1}\end{array}$ & \multirow{4}{*}{$\mathrm{M}_{1}$} \\
\hline & Iogurte & $\begin{array}{l}(10 / 28) 35,7 \\
(3 / 28) 10,7 \\
(5 / 28) 17,9 \\
(10 / 28) 35,7 \\
\end{array}$ & $\begin{array}{l}<0,01 \mu \mathrm{g} \mathrm{L}^{-1} \\
0,01-0,024 \mu \mathrm{g} \mathrm{L}^{-1} \\
0,025-0,05 \mu \mathrm{g} \mathrm{L}^{-1} \\
>0,05 \mu \mathrm{g} \mathrm{L}^{-1}\end{array}$ & \\
\hline & Iogurte coado (Labneh) & $\begin{array}{l}(3 / 27) 11,1 \\
(2 / 27) 7,4 \\
(22 / 27) 81,5\end{array}$ & $\begin{array}{l}<0,01 \mu \mathrm{g} \mathrm{L}^{-1} \\
0,025-0,05 \mu \mathrm{g} \mathrm{L}^{-1} \\
>0,05 \mu \mathrm{g} \mathrm{L}^{-1}\end{array}$ & \\
\hline & Iogurte Ayran & $\begin{array}{l}(1 / 9) 11,1 \\
(1 / 9) 11,1 \\
(3 / 9) 33,3\end{array}$ & $\begin{array}{l}<0,01 \mu \mathrm{g} \mathrm{L}^{-1} \\
0,01-0,024 \mu \mathrm{g} \mathrm{L}^{-1} \\
0,025-0,05 \mu \mathrm{g} \mathrm{L}^{-1}\end{array}$ & \\
\hline
\end{tabular}




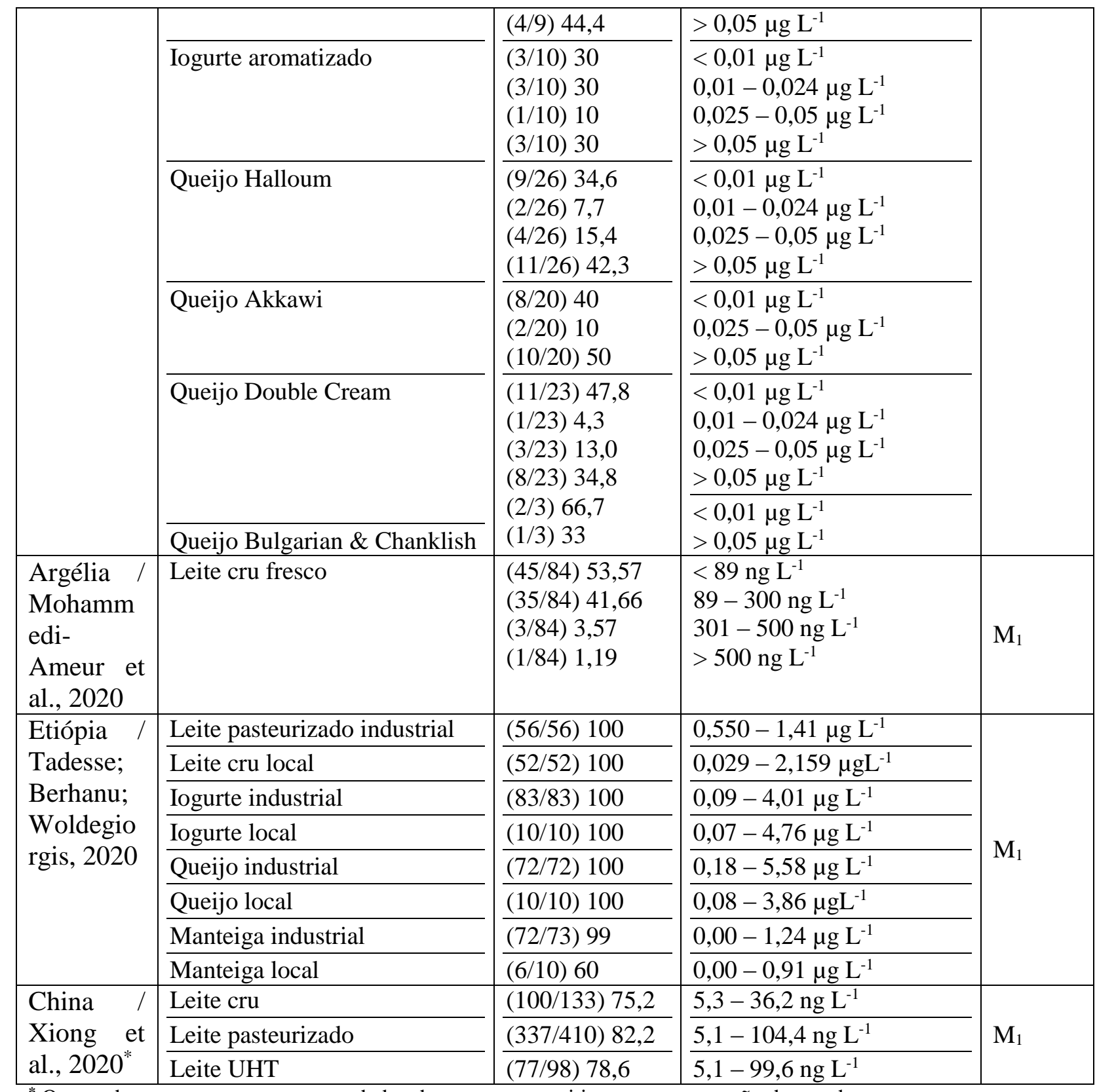

" Os estudos apresentaram somente dados das amostras positivas. - amostra não detectada.

Visando garantir a segurança do alimento, métodos de descontaminação que proporcionem a remoção e/ou redução da micotoxina, sem a formação de resíduos tóxicos, mantendo o valor nutricional $\mathrm{e}$ as propriedades tecnológicas dos alimentos, tem sido estudados (CAMPAGNOLLO et a., 2016; PARK, 2002; SANTOS et al., 2014). Destacam-se os métodos biológicos que fazem uso de enzimas ou micro-organismos, tendo como principal vantagem a eficiência quando comparado com as metodologias que fazem uso de agentes químicos e físicos (FAZELI et al., 2009; WU et al., 2009). 


\section{Bactérias ácido láticas}

Os micro-organismos mais estudados para descontaminação das AFLAs têm sido as bactérias ácido láticas (BAL), uma vez que são reconhecidas por serem organismos seguros e conseguirem se ligar com a toxina. As BAL são micro-organismos probióticos, que têm como característica a produção de ácido lático, são Gram-positivas, não produzem catalase e oxidase, e podem produzir reuterina, reconhecida como antifúngico, quando há glicerol no meio que irá ocorrer à fermentação (DALIÉ; DESCHAMPS; FORGET-RICHARD, 2010; GOURAMA; BULLERMAN, 1995; LINDGREN; DROGOSZ, 1990). Os Lactobacillus spp. são um gênero das BAL amplamente utilizado em alimentos crus, mas também podem ser aplicados em alimentos fermentados para maior preservação destes (GOURAMA; BULLERMAN, 1995). Além disso, estas bactérias fornecem propriedades funcionais e melhorias sensoriais ao produto (FABIAN et al., 2008).

A inibição do crescimento de micro-organismos produtores de AFLAs, bem como o efeito do uso de BAL tem sido avaliados em estudos in vivo (ABBÈS et al., 2016; CHEN et al., 2019; GOMAA; ABDELALL; EL-MAHDY, 2018; GUIMARÃES et al., 2018; JEBALI et al., 2018; NATEGHI et al., 2016; NDUTI et al., 2016; ONILUDE et al., 2005; SALAHABBÈS et al., 2015), e. alguns já comprovaram a capacidade dessas bactérias em reduzir ou degradar níveis da micotoxina in vitro (Quadro 2).

Quadro 2. Uso de bactérias ácido láticas na descontaminação de aflatoxinas em leite e derivados lácteos.

\begin{tabular}{|c|c|c|c|}
\hline $\begin{array}{l}\text { Autores } \\
\text { (ano) }\end{array}$ & Micro-organismo (s) & $\begin{array}{l}\text { AFLAs / } \\
\text { Meio de } \\
\text { descontamin } \\
\text { acão }\end{array}$ & Principais resultados \\
\hline $\begin{array}{ll}\text { Pierides et } \\
\text { al }(2000)\end{array}$ & $\begin{array}{l}\text { Lactobacillus } r \text { acidophillus } \\
\text { LA1; L. gasseri ATCC 33323; } \\
\text { L. rhamnosus GG; L. } \\
\text { rhamnosus LC-705; L. } \\
\text { rhamnosus 1/3; Lactococcus } \\
\text { lactis ssp. ARH74 }\end{array}$ & $\begin{array}{l}\mathrm{M}_{1}(0,15 \mu \mathrm{g} \\
\left.\mathrm{mL}^{-1}\right) / \mathrm{PBS}, \\
\text { leite integral } \\
\text { e leite } \\
\text { desnatado }\end{array}$ & $\begin{array}{l}77,0 \% \text { de redução com } L \text {. } \\
\text { rhamnosus GG viável no } \\
\text { período de } 4 \text { h em PBS. } 76,1 \% \\
\text { de descontaminação usando } L \text {. } \\
\text { rhamnosus LC-705 durante } 24 \\
\text { h em PBS; } 69,9 \text { e } 63,6 \% \text { de } \\
\text { diminuição em leite desnatado } \\
\text { e integral. }\end{array}$ \\
\hline $\begin{array}{l}\text { Haskard et } \\
\text { al (2001) }\end{array}$ & $\begin{array}{l}\text { Lactobacillus rhamnosus GG; } \\
\text { L. rhamnosus LC-705; L. } \\
\text { acidophilus LC1; L. lactis } \\
\text { subsp. lactis; L. acidophilus } \\
\text { ATCC 4356; L. plantarum; L. } \\
\text { casei Shirota; L. delbrueckii } \\
\text { subsp. bulgaricus; L. }\end{array}$ & $\begin{array}{l}\mathrm{B}_{1} \quad(10 \quad \mathrm{ng} \\
\left.\mathrm{mL}^{-1}\right) / \mathrm{PBS}\end{array}$ & $\begin{array}{l}\text { L. rhamnosus GG e } L \text {. } \\
\text { rhamnosus LC-705 ligaram } \\
78,9 \text { e } 76,5 \% \text { em } 4 \quad \mathrm{~h} \\
\text { respectivamente, e após } \\
\text { lavagens com PBS mantiveram } \\
\text { 49,5 e } 37,8 \% \text { da micotoxina. }\end{array}$ \\
\hline
\end{tabular}




\begin{tabular}{|c|c|c|c|}
\hline & $\begin{array}{lr}\text { helveticus; } & \text { Propionibacterium } \\
\text { freudenreichii } & \text { subsp. } \\
\text { shermanii JS; } & \text { Lactococcus } \\
\text { lactis subsp. } & \text { cremoris; } \\
\text { Streptococcus thermophilus }\end{array}$ & & \\
\hline $\begin{array}{l}\text { Kabak; Var } \\
\text { (2008) }\end{array}$ & $\begin{array}{l}\text { Lactobacillus } \quad \text { acidophilus } \\
\text { NCC 12; L. acidophilus NCC } \\
\text { 36; L. acidophilus NCC 68; L. } \\
\text { rhamnosus; Bifidobacterium } \\
\text { bifidum Bb13; B. bifidum NCC } \\
381\end{array}$ & $\begin{array}{l}\mathrm{M}_{1}(5 ; 10 ; 20 \\
\left.\mathrm{ng} \mathrm{mL}^{-1}\right) / \\
\text { PBS e leite }\end{array}$ & 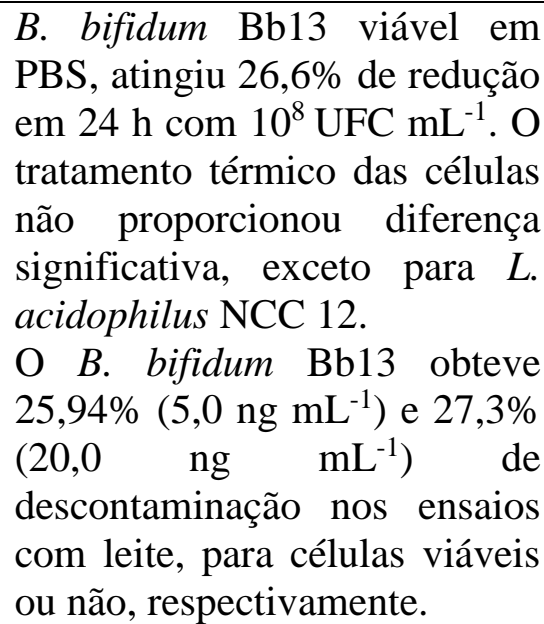 \\
\hline $\begin{array}{l}\text { Bovo et al } \\
\text { (2013) }\end{array}$ & 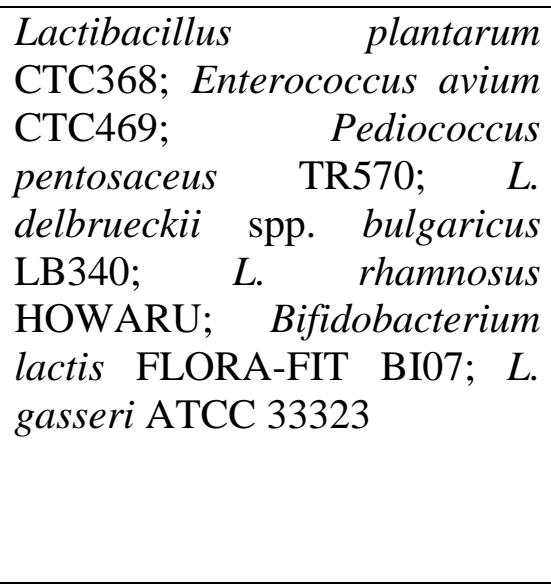 & $\begin{array}{l}\mathrm{M}_{1}(0,15 \mu \mathrm{g} \\
\mathrm{mL}^{-1} \text { no } \\
\mathrm{PBS}) \text { e }(0,5 \\
\mu \mathrm{g} \mathrm{L}^{-1} \text { no } \\
\text { leite }) / \mathrm{PBS} \text { e } \\
\text { leite } \\
\text { desnatado }\end{array}$ & $\begin{array}{l}\text { O tratamento com calor teve } \\
\text { maior capacidade de ligação } \\
\text { com a aflatoxina, usando } L \text {. } \\
\text { rhamnosus. A estabilidade do } \\
\text { complexo foi mais estável nas } \\
\text { células não viáveis. } L \text {. } \\
\text { bulgaricus atingiu } 65,6 \text { e } \\
69,1 \% \text { de ligação em PBS com } \\
15 \text { min e } 24 \text { h; no ensaio em } \\
\text { leite B. lactis obteve } 37,6 \text { e } \\
32,54 \% \text { de ligação em } 4 \text { e } 37 \\
{ }^{\circ} \text { C. }\end{array}$ \\
\hline $\begin{array}{l}\text { Ghazvini et } \\
\text { al (2016) }\end{array}$ & $\begin{array}{l}\text { Bifidobacterium bifidum PTCC } \\
\text { 1644; Lactobacillus fermentum } \\
\text { PTCC 1744; Aspergillus } \\
\text { parasiticus } \text { PTCC } 5286\end{array}$ & $\begin{array}{l}\mathrm{B}_{1} \text { e } \mathrm{G}_{1}(125 \\
\mathrm{ppb}) ; \mathrm{B}_{2} \text { e } \mathrm{G}_{2} \\
(25 \mathrm{ppb}) \quad / \\
\text { Caldo } \\
\text { tríptico de } \\
\text { soja }\end{array}$ & $\begin{array}{l}\text { B. bifidum diminuiu } \mathrm{AFLAB}_{1} \text {, } \\
\mathrm{AFLAG}_{1} \text {, e } \mathrm{AFLAG}_{2} \text { em } \\
99,9 \% \text { e AFLAB } \mathrm{B}_{2} \text { em } 99,8 \% \text {. } \\
L . \text { fermentum reduziu em } \\
99,9 \% \text { todas micotoxinas. } B . \\
\text { bifidum e } L . \text { fermentum } \\
\text { reduziram o crescimento } \\
\text { fúngico em } 81,6 \text { e } 77 \% \text {, } \\
\text { respectivamente. }\end{array}$ \\
\hline $\begin{array}{l}\text { Sedaghat et } \\
\text { al (2016) }\end{array}$ & $\begin{array}{l}\text { Lactobacillus plantarum PIN; } \\
\text { L. plantarum CAG23; L. casei } \\
\text { D31; L. pentosus H39; L. } \\
\text { plantarum NBRC 107151; L. } \\
\text { plantarum KU13; Aspergillus } \\
\text { flavus PTCC 5004 e A. } \\
\text { parasiticus PTCC 5286 }\end{array}$ & $\begin{array}{l}\text { - I Queijo } \\
\text { fresco }\end{array}$ & $\begin{array}{l}\text { L. plantarum PIN }\left(10^{8} \text { UFC }\right. \\
\left.\mathrm{mL}^{-1}\right) \text { apresentou a melhor } \\
\text { atividade antifúngica, } \\
\text { proporcionando um atraso de } \\
19 \text { e } 22 \text { dias no crescimento de } \\
\text { A. flavus e A. parasiticus, } \\
\text { respectivamente a temperatura } \\
\text { de armazenamento em } 4{ }^{\circ} \mathrm{C} \text {. }\end{array}$ \\
\hline $\begin{array}{l}\text { Ismail et al } \\
(2017)\end{array}$ & $\begin{array}{lrr}\text { Lactobacillus } & \text { plantarum } \\
\text { NRRL B-4496; L. helveticus } \\
\text { ATCC 12046; Lactococcus }\end{array}$ & $\begin{array}{l}\mathrm{M}_{1}(0,05 ; 0,1 \\
\left.\mu \mathrm{g} \quad \mathrm{L}^{-1}\right) \quad / \\
\text { Leite }\end{array}$ & $\begin{array}{l}\text { Houve } 100 \% \text { de ligação com } S \text {. } \\
\text { cerevisiae e L. helveticus na } \\
\text { mistura com os quatro micro- }\end{array}$ \\
\hline
\end{tabular}




\begin{tabular}{|c|c|c|c|}
\hline & $\begin{array}{l}\text { lactis JF 3102; Saccharomyces } \\
\text { cerevisiae HR } 125^{\mathrm{a}}\end{array}$ & & $\begin{array}{l}\text { organismos }\left(10^{10} \text { células } \mathrm{mL}^{-1}\right. \\
\left.\text { e } 0,05 \mu \mathrm{g} \mathrm{L}^{-1} \text { de AFLAM }\right) . L . \\
\text { plantarum e Lactococcus lactis } \\
\text { obtiveram } 80 \text { e } 76 \% \text { de } \\
\text { ligação. A concentração de } 0,1 \\
\mu \mathrm{g} \mathrm{L} \mathrm{L}^{-1} \text { de AFLAM } \text { A }_{1} \text { gerou } 92 ; \\
87 ; 85 ; 77 \text { e } 73 \% \text { de ligação } \\
\text { com } S . \text { cerevisiae; a mistura de } \\
\text { todos organismos, } L \text {. } \\
\text { helveticus, L. plantarum e } \\
\text { Lactococcus } \\
\text { respectivamente. }\end{array}$ \\
\hline $\begin{array}{l}\text { Kamyar; } \\
\text { Movassagh } \\
\text { ghazani, } \\
\text { (2017). }\end{array}$ & \begin{tabular}{lrc} 
Grupo 1 & - & Lactobacillus \\
acidophilus; & Bifidobacterium \\
BB-12; & \multicolumn{2}{c}{ Streptococcus } \\
thermophiles; & grupo $2 \quad-$ \\
Lactococcus & lactis & subsp. \\
cremoris; & \multicolumn{2}{c}{ Leuconostoc; } \\
Lactococcus & lactis & subsp. \\
lactis; grupo & - Debaromyces \\
hansenii; & Kluyveromyces \\
marxians subsp. marxianus
\end{tabular} & $\begin{array}{l}\text { M }(150 ; 200 \\
\left.; 250 \mathrm{ng} \mathrm{L^{-1 }}\right) \\
/ \quad \text { Kefir } \\
\text { utilizando } \\
\text { leite }\end{array}$ & $\begin{array}{l}\text { O maior nível de diminuição } \\
\text { da AFLA foi } 65 \% \text { aplicando } L \text {. } \\
\text { acidophilus, } B . \quad \mathrm{BB}-12, \quad S \text {. } \\
\text { thermophiles e } 200 \mathrm{ng} \mathrm{L}^{-1} \text {. }\end{array}$ \\
\hline $\begin{array}{l}\text { Sarlak et al } \\
(2017)\end{array}$ & 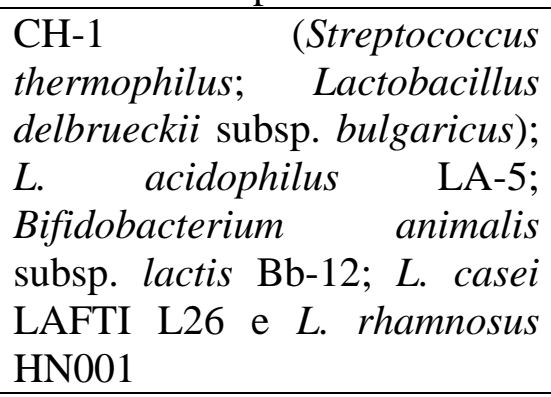 & $\begin{array}{l}\mathrm{M}_{1}(0,5 \mathrm{ppb}) \\
/ \quad \text { Leite } \\
\text { fermentado }\end{array}$ & $\begin{array}{l}\text { L. acidophilus } \text { LA-5 }(7 \text { log } \\
\text { UFC } \mathrm{mL}^{-1} \text { ) e pH } \text { final } \\
\text { fermentativo em } 4,5 \text { em } 28 \\
\text { dias de armazenamento, } \\
\text { descontaminou } 98,8 \% \text { da } \\
\text { AFLA. }\end{array}$ \\
\hline $\begin{array}{l}\text { Taheur et al } \\
\text { (2017) }\end{array}$ & $\begin{array}{l}\text { Bactérias e leveduras isoladas } \\
\text { de grãos e leite do kefir }\end{array}$ & $\begin{array}{l}\text { B }_{1}(1 \mu \mathrm{g} \mathrm{mL} \\
\left.{ }^{1}\right) / \text { Leite e } \\
\text { em caldo } \\
\text { Man, Rogosa } \\
\text { e Sharpe e } \\
\text { extrato de } \\
\text { levedura } \\
\text { peptona e } \\
\text { dextrose }\end{array}$ & $\begin{array}{l}\text { Lactobacillus kefiri e } \\
\text { Kazachstania servazzii ligaram } \\
80 \text { e } 74 \% \text { da AFLAB } \text { em leite, }_{1} \\
\text { respectivamente, a estabilidade } \\
\text { do complexo liberaram } 66 \text { e } \\
35 \% \text {, após o tratamento em pH } \\
7 ; 3 \text { e } 8 .\end{array}$ \\
\hline $\begin{array}{l}\text { Abdelmotili } \\
\text { b et al } \\
(2018)\end{array}$ & $\begin{array}{l}\text { Lactobacillus plantarum DSM } \\
20174 ; \text { L. acidophilus DSM } \\
20079 ; \quad \text { Bifidobacterium } \\
\text { bifidum DSM 20082; } \\
\text { Kluyveromyces lactis CBS } \\
\text { 2359; Saccharomyces } \\
\text { cerevisiae ATCC } 64712 \\
\end{array}$ & $\begin{array}{l}\mathrm{M}_{1}(50 \mathrm{ng} \\
\left.\mathrm{mL}^{-1}\right) / \mathrm{PBS} \\
\text { e leite }\end{array}$ & $\begin{array}{l}\text { A maior redução foi utilizando } \\
\text { o efeito combinatório das BAL } \\
\text { tratadas termicamente na } \\
\text { concentração de } 5 \times 10^{9} \text { UFC } \\
\mathrm{mL}^{-1} \text {, conseguindo taxas de } \\
87,9 \text { e } 90,9 \% \text { em PBS e leite, } \\
\text { respectivamente. }\end{array}$ \\
\hline $\begin{array}{l}\text { Barukcic et } \\
\text { al (2018) }\end{array}$ & $\begin{array}{lr}\text { Bifidobacterium } & \text { animalis } \\
\text { subsp. lactis } & \text { BB-12, } \\
\text { Lactobacillus casei } & \text { LC-01; } \\
\text { cultura combinada } & \text { ABT-5 de }\end{array}$ & $\begin{array}{l}\mathrm{M}_{1}(50 \mathrm{ng} \\
\left.\mathrm{kg}^{-1}\right) / \text { Leite } \\
\text { fermentado }\end{array}$ & 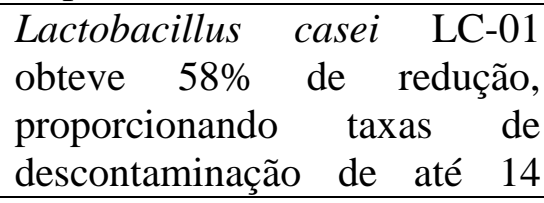 \\
\hline
\end{tabular}




\begin{tabular}{|c|c|c|c|}
\hline & $\begin{array}{l}\text { L. acidophilus La-2; BB-12 e } \\
\text { Streptococcus thermophilus; } \\
\text { culturas comerciais de iogurte } \\
\text { YC-380; mesófilos CHN-19; } \\
\text { kefir XPL-1 }\end{array}$ & & dias. \\
\hline $\begin{array}{l}\text { Delgado et } \\
\text { al (2018) }\end{array}$ & $\begin{array}{lr}\text { A proteína avaliada isolada ou } \\
\text { em combinação } & \text { com } \\
\text { Debaryomyces } & \text { hansenii } \\
\text { FHSCC } 253 \mathrm{H} & \text { e/ou } \\
\text { Pediococcus acidilactici fargo } \\
\text { 35; Aspergillus parasiticus } \\
\text { CECT 2682 }\end{array}$ & $\begin{array}{l}\mathrm{B}_{1} \text { e } \mathrm{G}_{1} / \\
\text { Extrato de } \\
\text { levedura, } \\
\text { extrato de } \\
\text { levedura } \\
\text { enriquecido } \\
\text { com cloreto } \\
\text { de cálcio e } \\
\text { queijo } \\
\text { fermentado a } \\
\text { seco }\end{array}$ & $\begin{array}{l}\text { O tratamento com a proteína e } \\
\text { Debaryomyces hansenii } \\
\text { FHSCC } 253 \mathrm{H} \text { inibiu o } \\
\text { crescimento do } A \text {. parasiticus } \\
\text { de } 5 \text { até } 15 \text { dias, com } \\
\text { concentrações de AFLAB } 1 \\
\text { menores que } 4 \text { ppb (LOD) e } \\
\text { AFLAG menores que } 1,5 \text { ppb } \\
\text { (LOD). }\end{array}$ \\
\hline $\begin{array}{l}\text { Ghanbari et } \\
\text { al (2018) }\end{array}$ & $\begin{array}{l}\text { Lactobacillus plantarum 1058; } \\
\text { L. delbrueckii subsp. lactis } \\
\text { 1057; Aspergillus parasiticus } \\
\text { ATCC } 15517\end{array}$ & $\begin{array}{l}\text { Expressão do } \\
\text { gene aflR / } \\
\text { Microdiluiçã } \\
\text { o em caldo }\end{array}$ & $\begin{array}{l}\text { A } \mathrm{AFLAG}_{2} \text { foi inibida a níveis } \\
\text { abaixo do limite de detecção e } \\
\text { as AFLAB } \mathrm{AFLAB}_{2} \text { e } \\
\mathrm{AFLAG}_{1} \text { foram menos } \\
\text { detectadas na exposição com } \\
\text { L. plantarum, obtendo } \\
\text { concentrações } 50600 ; 2200 ; \\
25600 \text { e } 78400 \text { ppb, } \\
\text { respectivamente; A análise de } \\
\text { PCR demonstrou redução na } \\
\text { expressão do gene aflR, em } \\
\text { ambas as BAL. }\end{array}$ \\
\hline $\begin{array}{l}\text { Kuharic et } \\
\text { al (2018) }\end{array}$ & $\begin{array}{l}\text { Lactobacillus plantarum SM1; } \\
\text { L. plantarum SMB; L. } \\
\text { plantarum MM; L. plantarum } \\
\mathrm{KM} \text {; L. paracasei } \mathrm{KM} \text {; L. } \\
\text { rhamnosus } \mathrm{KM} \text { L. plantarum } \\
\text { SMA; L. plantarum SS1; L. } \\
\text { helveticus S9; Lactococcus } \\
\text { lactis 5MS1 }\end{array}$ & $\begin{array}{l}\mathrm{M}_{1}(0,5 \mu \mathrm{g} \mathrm{L} \\
\left.{ }^{1}\right) / \text { Leite }\end{array}$ & $\begin{array}{l}\text { L. plantarum KM viável ou } \\
\text { tratado termicamente foi capaz } \\
\text { de ligar a } \mathrm{AFLAM}_{1} \text {, obtendo } \\
92,7 \text { e } 94,5 \% \text { de ligação, } \\
\text { respectivamente, em } 4 \text { h de } \\
\text { cultivo. }\end{array}$ \\
\hline $\begin{array}{l}\text { Marrez et al } \\
\text { (2018) }\end{array}$ & $\begin{array}{l}\text { Lactobacillus acidophilus CH- } \\
2 ; \text { Streptococcus thermophilus } \\
\text { CH-1; L. rhamnosus B-445; L. } \\
\text { plantarum EMCC-1039 }\end{array}$ & $\begin{array}{l}\mathrm{B}_{1}(50 \mathrm{ng} \\
\left.\mathrm{mL}^{-1}\right) / \text { Leite } \\
\text { integral } \mathrm{e} \\
\text { caldo Man, } \\
\text { Rogosa } \mathrm{e} \\
\text { Sharpe }\end{array}$ & $\begin{array}{l}\text { No caldo Man, Rogosa e } \\
\text { Sharpe as maiores reduções de } \\
\text { AFLAB }{ }_{1} \text { ocorreram com S. } \\
\text { thermophilus CH-1, seguido de } \\
\text { L. plantarum EMCC-1039, } \\
\text { com } 65,7 \text { e } 57,7 \% \text { de } \\
\text { descontaminação. L. plantarum } \\
\text { EMCC-1039, L. rhamnosus B- } \\
445 \text { e } S . \text { thermophilus CH-1 } \\
\text { propiciaram descontaminações } \\
\text { de } 85,2 ; 79,4 \text { e } 65,2 \% \text {, } \\
\text { respectivamente, no leite. }\end{array}$ \\
\hline $\begin{array}{l}\text { Sokoutifar } \\
\text { et al (2018) }\end{array}$ & $\begin{array}{lrr}\text { Lactobacillus } & \text { acidophilus } \\
\text { PTCC } 1643 ; \quad \text { L. } & \text { plantarum }\end{array}$ & $\begin{array}{l}\mathrm{M}_{1}(180 \mathrm{pg} \\
\left.\mathrm{mL}^{-1}\right) / \text { Leite }\end{array}$ & $\begin{array}{l}\text { L. plantarum PTCC } 1058 \\
\text { apresentou maior eficiência a }\end{array}$ \\
\hline
\end{tabular}




\begin{tabular}{|c|c|c|c|}
\hline & PTCC 1058 & $\begin{array}{l}\text { fermentado } \\
\text { industrial e } \\
\text { tradicional }\end{array}$ & $\begin{array}{l}37{ }^{\circ} \mathrm{C} \text { com } 100 \% \text { de redução } \\
\text { da micotoxina nos primeiros } \\
10 \text { dias para o leite fermentado } \\
\text { tradicional e industrial. }\end{array}$ \\
\hline $\begin{array}{l}\text { Sevim et al } \\
(2019)\end{array}$ & $\begin{array}{l}\text { Bifidobacterium } \\
\text { ATCC 35914; B. animalis } \\
\text { subsp. animalis ATCC 27672; } \\
\text { Lactobacillus } \quad \text { plantarum } \\
\text { ATCC 10697; culturas } \\
\text { iniciadoras de iogurte (L. } \\
\text { delbrueckii subsp. bulgaricus } \\
\text { RSKK 04087 e Streptococcu } \\
\text { thermophiles RSKK 01017) }\end{array}$ & $\begin{array}{l}\mathrm{M}_{1} \\
\left(100 \mathrm{ng} \mathrm{mL}^{-}\right. \\
\left.{ }^{1}\right) / \text { Iogurte e } \\
\text { PBS }\end{array}$ & $\begin{array}{l}\text { A ligação da micotoxina em } \\
\text { iogurte sem a suplementação } \\
\text { da inulina obteve os melhores } \\
\text { resultados com } B \text {. bifidum e } B \text {. } \\
\text { animalis subsp. animalis após } \\
\text { um dia de armazenamento com } \\
60,8 \% \text { de ligação. Após } 10 \\
\text { dias de armazenamento } L \text {. } \\
\text { plantarum e B. bifidum } \\
\text { atingiram 55,1\% de ligação. A } \\
\text { adição de inulina obteve o } \\
\text { máximo de ligação com } L \text {. } \\
\text { plantarum e B. bifidum, } 70,5 \% \\
\text { após um dia de } \\
\text { armazenamento. O ensaio com } \\
\text { PBS obteve resultados de } \\
\text { ligação inferiores ao } \\
\text { encontrado no iogurte. }\end{array}$ \\
\hline $\begin{array}{l}\text { Wochner et } \\
\text { al (2019) }\end{array}$ & Lactobacillus acidophilus La-5 & $\begin{array}{l}\mathrm{B}_{1}(3,25 \text { a } \\
\left.6,0 \mu \mathrm{g} \mathrm{L}^{-1}\right) \mathrm{e} \\
\mathrm{M}_{1}(1,0 \text { a } 2,0 \\
\left.\mu \mathrm{g} \quad \mathrm{L}^{-1}\right) \\
\text { Leite }\end{array}$ & $\begin{array}{l}\text { A maior redução de } \text { AFLAB }_{1} \\
\text { foi utilizando a BAL, } \beta \text { - } \\
\text { glucana e polidextrose } \\
\text { atingindo } 35,5 \% \text {, e a redução } \\
\text { de } \text { AFLAM }_{1} \text { foi de } 71,5 \% \text {. A } \\
\text { melhor condição experimental } \\
\text { foi } 6,5 \mu \mathrm{g} \mathrm{L}^{-1} \text { de } A F L A B_{1} \text { e } 2,0 \\
\mu \mathrm{g} \mathrm{L}^{-1} \text { de AFLAM } \mathrm{AM}_{1} \text { com tempo } \\
\text { de incubação de } 0 \mathrm{~h} \text { e adição } \\
\text { de probióticos e inulina } \\
(0,75 \%) \text {. }\end{array}$ \\
\hline $\begin{array}{l}\text { Gonçalves } \\
\text { et al (2020) }\end{array}$ & $\begin{array}{lr}\text { Lactobacillus } & \text { rhamnosus; } \\
\text { Lactococcus } & \text { lactis; } \\
\text { Saccharomyces cerevisiae }\end{array}$ & $\begin{array}{l}\mathrm{M}_{1}(0,5 \mu \mathrm{g} \\
\left.\mathrm{kg}^{-1}\right) / \text { Queijo } \\
\text { Minas frescal }\end{array}$ & $\begin{array}{l}\text { As BAL obtiveram } 94 \% \text { de } \\
\text { redução com } 10 \text { dias de } \\
\text { armazenamento. Avaliando } \\
\text { somente a levedura, atingiu-se } \\
100 \% \text { em } 20 \text { dias de } \\
\text { armazenamento. As BAL e a } \\
\text { levedura diminuiram } 100 \% \text { em } \\
10 \text { dias de armazenamento. }\end{array}$ \\
\hline
\end{tabular}

É possível observar no Quadro 2, que a aplicação de Lactobacillus plantarum, L. rhamnosus, L. bulgaricus e Bifidobacterium bifidum, viáveis ou tratados termicamente, em leite ou derivados lácteos, têm resultados promissores de descontaminação. Gonçalves et al (2018) atingiu níveis de 40 a 3670 ng L ${ }^{-1}$ de AFLAM $_{1}$ em leite, fazendo uso das condições experimentais desenvolvidas por Sarlak et al (2017), que obteve 98,8\% de descontaminação 
em leite fermentado com contaminação inicial de 0,5 ppb para AFLAM $_{1}$, utilizando concentração inicial de BAL em $7 \log \mathrm{UFC} \mathrm{mL} \mathrm{m}^{-1}$ e temperatura de $40{ }^{\circ} \mathrm{C}$ com pH final em 4,5 e Taheur et al (2017), por meio do cultivo por $24 \mathrm{~h}$ a $25^{\circ} \mathrm{C}$, fazendo uso de leite contaminado com $1 \mu \mathrm{g} \mathrm{mL}^{-1}$ de $\mathrm{AFLAB}_{1}$, atingiu $80 \%$ de redução, demonstrando as possibilidade de reduções dentro das concentrações nas diferentes legislações vigentes. Porém, a redução destes contaminantes dependerá dos micro-organismos que serão utilizados, das concentrações de BAL e de aflatoxina presente, tempo de contato entre bactéria e aflatoxina e, a estabilidade deste complexo.

\section{Considerações Finais}

O uso de BAL em leite e derivados contaminados com AFLAM1 e/ou AFLAB1 com o objetivo de reduzir e/ou degradar estes contaminantes é uma alternativa promissora, demonstrada pelos estudos apresentados nesta revisão. Entretanto ainda é necessário elucidar o mecanismo de ação entre os micro-organismos e as aflatoxinas, bem como avaliar a estabilidade deste complexo a fim de garantir que estes compostos não ofereçam risco à saúde humana.

\section{Referências}

ABBÈS, S.; SALAH-ABBÈS, J. B.; JEBALI, R.; YOUNES, R. B.; OUESLATI, R. Interaction of aflatoxin $B_{1}$ and fumonisin $B_{1}$ in mice causes immunotoxicity and oxidative stress: possible protective role using lactic acid bacteria. Journal of Immunotoxicology, v. 13, p. $1-9,2016$.

ABDELMOTILIB, N. M.; HAMAD, G. M.; ELDEREA, H. B.; SALEM, E. G.; SOHAIMY, S. A. E. Aflatoxin $M_{1}$ reduction in milk by a novel combination of probiotic bacterial and yeast strains. European Journal of Nutrition \& Food Safety, v. 8, p. 83 - 99, 2018.

AGÊNCIA NACIONAL DE VIGILÂNCIA SANITÁRIA- ANVISA. Resolução de Diretoria Colegiada (RDC) número 7 de 18 de Fevereiro de 2011. Limites máximos tolerados para micotoxinas em alimentos. Diário Oficial da União. Disponível em: http://portal.anvisa.gov.br/documents/10181/2968262/\%282\%29RDC_07_2011_COMP.pdf/4 2310948-a1c5-4213-a467-1da97b8f4cae. Acesso em: 30 julho 2020.

ALAHLAH, N.; MAADOUDI, M. E.; BOUCHRITI, N.; TRIQUI, R.; BOUGTAIB, H. Aflatoxin $\mathrm{M}_{1}$ in UHT and poder milk marketed in the northern área of Morocco. Food Control, v. 114, p. 1 - 5, 2020.

AWASTHI, V.; BAHMAN, B.; THAKUR, L. K.; SINGH, S. K.; DUA, A.; GANGULY, S. Contaminants in milk and impact of heating: na assessment study. Indian Journal of Public Health, v. 56, p. 95 - 99, 2012. 
BAHRAMI, R.; SHAHBAZI, Y.; NIKOUSEFAT, Z. Aflatoxin $\mathrm{M}_{1}$ in milk and traditional dairy products from west parto f Iran: occurrence and seasonal variation with emphasis on risk assessment of human exposure. Food Control, v. 62, p. 250 - 256, 2016.

BAKIRCI, I. A study on the occurrence of aflatoxin $\mathrm{M}_{1}$ in milk and milk products produced in Van province of Turkey. Food Control, v. 12, p. 47 - 51, 2001.

BARUKCIC, I.; BILANDZIC, N.; MARKOV, K.; JAKOPOVIC, K. L.; BOZANIC, R. Reduction in aflatoxin $\mathrm{M}_{1}$ concentration during production and storage of selected fermented milks. Intermational Journal of Dairy Technology, v. 71, p. 734 - 740, 2018.

BECKER-ALGERI, T. A.; CASTAGNARO, D.; BORTOLI, K.; SOUZA, C.; DRUNKLER, D. A.; BADIALE-FURLONG, E. Micotoxins in bovine milk and dairy products: a review. Journal of Food Science, v. 81, p. R544 - R552, 2016.

BECKER-ALGERI, T. A.; SOUZA, C.; BORTOLI, K.; CASTAGNARO, D.; SCAGLIONI, P. T.; DRUNKLER, D. A.; DORS, G.; VALDERRAMA, P.; BADIALE-FURLONG, E. Seasonal variation of milk quality: physicochemical, microbiological, and toxicological. Journal of Food Safety, v. e12796, 2020.

BENKERROUM, N. Chronic and acute toxicities of aflatoxinas: mechanisms of action. International Journal of Environmental Research and Public Health, v. 17, p. $1-28$, 2019.

BENNETT, J. W.; KLICH, M. Mycotoxins. Clinical Microbiology Reviews, v. 16, p. 497 $516,2003$.

BOVO, F.; CORASSIN, C. H.; ROSIM, R. E.; OLIVEIRA, C. A. F. Efficiency of lactic acid bacteria strains for decontamination of aflatoxin $\mathrm{M}_{1}$ in phosphate buffer saline solution and skimmed milk. Food and Bioprocess Technology, v. 6, p. 2230 - 2234, 2013.

BRASIL. Instrução Normativa (IN) número 76, de 26 de Novembro de 2018. Regulamento técnico de identidade e qualidade de leite cru refrigerado. Ministério da Agricultura, Pecuária e Abastecimento, 2018. Disponível em: http://sistemasweb.agricultura.gov.br/sislegis/action/detalhaAto.do?method=consultarLegislac aoFederal. Acesso em: 17 julho 2020.

BRASIL. Instrução Normativa (IN) número 77, de 26 de Novembro de 2018. Critérios e procedimentos para a produção, acondicionamento, conservação, transporte e recepção do leite cru em estabelecimentos registrados no serviço de inspeção oficial. Ministério da Agricultura, Pecuária e Abastecimento, 2018a. Disponível em: http://sistemasweb.agricultura.gov.br/sislegis/action/detalhaAto.do?method=consultarLegislac aoFederal. Acesso em: 17 julhon 2020.

BRASIL. Portaria número 7, de 09 de Novembro de 1988. Baixa os padrões mínimos de matéria-prima destinada à alimentação animal. Ministério da Agricultura, Pecuária e Abastecimento, $1988 . \quad$ Disponível em: http://sistemasweb.agricultura.gov.br/sislegis/action/detalhaAto.do?method=consultarLegislac aoFederal. Acesso em: 01 agosto 2020. 
CAMPAGNOLLO, F. B.; GANEV, K. C.; KHANEGHAH, A. M.; PORTELLA, J.; CRUZ, A. G.; GRANATO, D.; CORASSIN, C. H.; OLIVEIRA, C. A. F.; SANT'ANA, A. S. The occurrence and effect of unit operations for dairy products processing on the fate of aflatoxin $\mathrm{M}_{1}$ : a review. Food Control, v. 68, p. $310-329,2016$.

CHAVARRÍA， G.; GRANADOS-CHINCHILLA， F.; ALFARO-CASCANTE， M.; MOLINA, A. Detection of aflatoxin $\mathrm{M}_{1}$ in milk, cheese and sour cream samples from Costa Rica using enzyme-assisted extraction and HPLC. Food Additives \& Contaminants: Part B: Surveillance, v. 8, p. 128 - 135, 2015.

COMISSÃO DA UNIÃO EUROPEIA. Comissão da Regulamentação da União Europeia número 165/2010 de 26 Fevereiro 2010. Determinação de teores máximos para certos contaminantes em alimentos, no que diz respeito às aflatoxinas. Comissão da Regulamentação, 2010. Disponível em: https://eurlex.europa.eu/LexUriServ/LexUriServ.do?uri=OJ:L:2010:050:0008:0012:EN:PDF. Acesso em: 31 julho 2020.

CREPPY, E. E. Update of survey, regulation and toxic effects of mycotoxins in Europe. Toxicology Letters, v. 127, p. 19 - 28, 2002.

DADZIE, M. A.; OPPONG, A.; OFORI, K.; ELEBLU, J. S.; IFIE, E. B.; BLAY, E.; OBENG-BIO, E. Distribution of Aspergillus flavus and aflatoxin accumulation in stored maize grains across three agro-ecologies in Ghana. Food Control, v. 104, p. 91 - 98, 2019.

DALIÉ, D. K. D.; DESCHAMPS, A. M.; RICHARD-FORGET, F. Lactic acid bacteria Potential for controlo f mould growth and mycotoxins: a review. Food Control, v. 21, p. 370 $-380,2010$.

DAOU, R.; AFIF, C.; JOUBRANE, K.; KHABBAZ, L. R.; MAROUN, R.; ISMAIL, A.; KHOURY, A. E. Occurrence of aflatoxin $\mathrm{M}_{1}$ in raw, pasteurized, UHT cow's milk, and dairy products in Lebanon. Food Control, v. 111, p. 1 - 29, 2020.

DELGADO, J.; RODRÍGUEZ, A.; GARCÍA, A.; NÚÑEZ, F.; ASENSIO, M. A. Inhibitory effect of PgAFP and protective cultures on Aspergillus parasiticus growth and aflatoxins production on dry-fermented sausage and cheese. Microorganisms - Open Access Journal, v. 6 , p. $1-16,2018$.

DEVECI, O. Changes in the concentration of aflatoxin $\mathrm{M}_{1}$ during manufacture and storage of White pickled cheese. Food Control, v. 18, p. 1103 - 1107, 2007.

FABIAN, E.; MAJCHRZAK, D.; DIEMINGER, B.; MEYER, E.; ELMADFA, I. Influence of probiotic and conventional yoghurt on the status of vitamins $\mathrm{B}_{1}, \mathrm{~B}_{2}$ and $\mathrm{B}_{6}$ in Young healthy women. Annals of Nutrition \& Metabolism, v. 52, p. 29 - 36, 2008.

FAZELI, M. R.; HAJIMOHAMMADALI, M.; MOSHKANI, A.; SAMADI, N.; JAMALIFAR, H.; KHOSHAYAND, M. R.; VAGHARI, E.; POURAGAHI, S. Aflatoxin B binding capacity of autochthonous strains of lactic acid bactéria. Journal of Food Protection, v. 72, p. $189-192,2009$. 
FERNANDES, A. M.; CORRÊA, B.; ROSIM, R. E.; KOBASHIGAWA, E.; OLIVEIRA, C. A. F. Distribution and stability of aflatoxin $\mathrm{M}_{1}$ during processing and storage of Minas Frescal cheese. Food Control, v. 24, p. 104 - 108, 2012.

FOOD \& DRUG ADMINISTRATION - FDA. CPG Sec. 527.400 whole milk, lowfat milk, skim milk - aflatoxin $\mathrm{M}_{1}$. Office of Regulatory Affairs and Center for Food and Applied Nutrition, 2005. Disponível em: https://www.fda.gov/regulatory-information/search-fdaguidance-documents/cpg-sec-527400-whole-milk-lowfat-milk-skim-milk-aflatoxin-m1.

Acesso em: 28 julho 2020.

FOOD \& DRUG ADMINISTRATION - FDA. Sec. 683.100 Action Levels for Aflatoxins in Animal Food. Office of Regulatory Affairs and Center for Veterinary Medicine, 2019. Disponível em: https://www.fda.gov/media/121202/download\#: :text=In\%201969\%2C\%20FDA\%20set\%20 an,to\%20the\%20lowest\%20possible\%20level.. Acesso em: 30 julho 2020.

GHANBARI, R.; AGHAEE, E. M.; REZAIE, S.; KHANIKI, G. J.; ALIMOHAMMADI, M.; SOLEIMANI, M.; NOORBAKHSH, F. The inhibitory effect of lactic acid bacteria on aflatoxin production and expression of aflR gene in Aspergillus parasiticus. Journal of Food Safety, v. 38, p. $1-6,2018$.

GHAZVINI, R. D.; KOUHSARI, E.; ZIBAFAR, E.; HASHEMI, S. J.; AMINI, A.; NIKNEJAD, F. Antifungal activity and aflatoxin degradation of Bifidobacterium bifidum and Lactobacillus fermentum against toxigenic Aspergillus parasiticus. The Open Microbiology Journal, v. 10, p. 197 - 201, 2016.

GOMAA, E. Z.; ABDELALL, M. F.; EL-MAHDY, O. M. Detoxification of aflatoxin $\mathrm{B}_{1}$ by antifungal compounds from Lactobacillus brevis and Lactobacillus paracasei, isolated from dairy products. Probiotics and Antimicrobial Proteins, v. 10, p. 201 - 209, 2018.

GONÇALVES, L.; ROSA, A. D.; GONZALES, S. L.; FELTES, M. M. C.; BADIALEFURLONG, E.; DORS, G. C. Incidence of aflatoxin $\mathrm{M}_{1}$ in fresh milk from small farms. Food Science and Technology, v. 37, p. $11-15,2017$.

GONÇALVES, K. D. M.; SIBAJA, K. V. M.; FELTRIN, A. C. P.; REMEDI, R. D.; GARCIA, S. O.; GARDA-BUFFON, J. Occurrence of aflatoxinas $\mathrm{B}_{1}$ and $\mathrm{M}_{1}$ in milk powder and UHT consumed in the city of Assomada (Cape Verde Islands) and Southern Brazil. Food Control, v. 93, p. $260-264,2018$.

GONÇALVES, B. L.; MUAZ, K.; COPPA, C. F. S. C.; ROSIM, R. E.; KAMIMURA, E. S.; OLIVEIRA, C. A. F.; CORASSIN, C. H. Aflatoxin $\mathrm{M}_{1}$ adsorption by non-viable cells of lactic acid bacteria and Saccharomyces cerevisiae strains in Frescal cheese. Food Research International, v. 136, p. $1-5,2020$.

GOURAMA, H.; BULLERMAN, L. B. Inhibition of growth and aflatoxin production of Aspergillus flavus by Lactobaacillus species. Journal of Food Protection, v. 58, p. 1249 1256, 1995. 
GOVARIS, A.; ROUSSI, V.; KOIDIS, P. A.; BOTSOGLOU, N. A. Distribution and stability of aflatoxin $\mathrm{M}_{1}$ during production and storage of yoghurt. Food Additives \& Contaminants, v. 19, p. $1043-1050,2002$.

GUIMARÃES, A.; SANTIAGO, A.; TEIXEIRA, J. A.; VENÂNCIO, A.; ABRUNHOSA, L. Anti-aflatoxigenic effect of organic acids produced by Lactobacillus plantarum. International Journal of Food Microbiology, v. 264, p. 31 - 38, 2018.

HASKARD, C. A.; EL-NEZAMI, H. S.; KANKAANPAA, P. E.; SALMINEN, S.; AHOKAS, J. T. Surface binding of aflatoxin $\mathrm{B}_{1}$ by lactic acid bactéria. Applied and Environmental Microbiology, v. 67, p. 3086 - 3091, 2001.

HASSANIN, N. I. Stability of aflatoxin $M_{1}$ during manufacture and storage of yoghurt, yoghurt-cheese and acidified milk. Journal of the Science of Food and Agriculture, v. 65, p. $31-34,1994$.

IHA, M. H.; BARBOSA, C. B.; OKADA, I. A.; TRUCKSESS, M. W. Aflatoxin $\mathrm{M}_{1}$ in milk and distribution and stability of aflatoxin $\mathrm{M}_{1}$ during production and storage of yoghurt and cheese. Food Control, v. 29, p. 1 - 6, 2013.

IQBAL, S. Z.; ASI, M. R.; MALIK, N. The seasonal variation of aflatoxin $\mathrm{M}_{1}$ in milk and dairy products and assessment of dietary intake in Punjab, Pakistan. Food Control, v. 79, p. $292-296,2017$.

ISMAIL, A.; LEVIN, R. E.; RIAZ, M.; AKHTAR, S.; GONG, Y. Y.; OLIVEIRA, C. A. F. Effect of diferente microbial concentrations on binding of aflatoxin $\mathrm{M}_{1}$ and stability testing. Food Control, v. 73, p. 492 - 496, 2017.

JEBALI, R.; SALAH-ABBÈS, J. B.; ABBÈS, S.; HASSAN, A. M.; ABDEL-AZIEM, S. H.; EL-NEKEETY, A. A.; OUESLATI, R.; ABDEL-WAHHAB, M. A. Lactobacillus plantarum alleviate aflatoxins $\left(\mathrm{B}_{1}\right.$ and $\left.\mathrm{M}_{1}\right)$ induced disturbances in the intestinal genes expression and DNA fragmentation in mice. Toxicon, v. 146, p. 13 - 23, 2018.

KABAK, B.; VAR, I. Factors affecting the removal of aflatoxin $\mathrm{M}_{1}$ from food model by Lactobacillus and Bifidobacterium strains. Journal of Environmental Science and Health, Part B: Pesticides, Food Contaminants, and Agricultural Wastes, v.43, p. 617 - 624, 2008.

KAMYAR, S.; MOVASSAGHGHAZANI, M. Reduction of aflatoxin $\mathrm{M}_{1}$ in milk using kefir starter. Iranian Journal of Toxicology, v. 11, p. 27 - 31, 2017.

KLEIN, P. J.; BUCKNER, R.; KELLY, J.; COULOMBE, R. A. J. Biochemical basis for the extreme sensitivity of turkeys to aflatoxin $B_{1}$. Toxicology and Applied Pharmacology, v. 165 , p. $45-52,2000$.

KUHARIĆ, Ž.; JAKOPOVIĆ, Ž.; ČANAK, I.; FRECE, J.; BOŠNIR, J.; PAVLEK, Ž.; IVEŠIĆ, M.; MARKOV, K. Removing aflatoxin $\mathrm{M}_{1}$ from milk with native lactic acid bacteria, centrifugation, and filtration. Archives of Industrial Hygiene and Toxicology, v. 69, p. $334-339,2018$. 
LINDGREN, S. E.; DOBROGOSZ, W. J. Antagonistic actiivities of lactic acid bacteria in food and feed fermentations. FEMS Microbiology Reviews, v. 87, p. 149 - 164, 1990.

LÓPEZ, C.; RAMOS, L.; RAMADÁN, S.; BULACIO, L.; PEREZ, J. Distribution of aflatoxin $\mathrm{M}_{1}$ in cheese obtained from milk artificially contamined. International Journal of Food Microbiology, v. 64, p. $211-215,2001$.

MARREZ, D. A.; SHAHY, E. M.; EL-SAYED, H. S.; SULTAN, Y. Y. Detoxification of aflatoxin $B_{1}$ in milk using lactic acid bacteria. Journal of Biological Sciences, v. 18, p. 144 $151,2018$.

MOHAMMEDI-AMEUR, S.; DAHMANE, M.; BRERA, C.; KARDJADJ, M.; BEMMAHDI, M. H. Occurrence and seasonla variation of aflatoxin $\mathrm{M}_{1}$ in raw cow milk collected from diferent regions of Algeria. Veterinary World, v. 13, p. 433 - 439, 2020.

MOSS, M. O. Recent studies of mycotoxins. Journal of Applied Microbiology Symposium Supplement, v. 84, p. 62S-76S, 1998.

MURPHY, P. A.; HENDRICH, S.; LANDGREN, C.; BRYANT, C.M. Food mycotoxins: an update. Journal of Food Science, v. 71, p. R51 - R65, 2006.

NATEGHI, F.; NOORBAKHSH, F.; LOTFALI, E.; REZAIE, S. Investigation the effects of Lactobacillus acidophilus and Lactobacillus casei on aflR gene expression in Aspergillus parasiticus by real time- PCR. Iranian Journal of Public Health, v. 45, p. 781 - 786, 2016.

NDUTI, N.; MCMILLAN, A.; SENEY, S.; SUMARAH, M.; NJERU, P.; MWANIKI, M.; REID, G. Investigating probiotic yoghurt to reduce an aflatoxin $\mathrm{B}_{1}$ biomarker among school children in eastern Kenya: preliminar study. International Dairy Journal, v. 63, p. 124 129, 2016.

OBREMSKI, K.; ZIELONKA, L.; GAJECKA, M.; JAKIMIUK, E.; GAJECKI, M. Mycotoxins - dairy cattle breeding problem. A case report. Bulletin Veterinary Institute in Pulawy, v. 53, p. $221-224,2009$.

O'BRIEN, M.; O'KIELY, P.; FORRISTAL, P. D.; FULLER, H. T. Fungi isolated from contaminated baled grass silage on farms in the Irish Midlands. FEMS Microbiology Letters, v. 247, p. $131-135,2005$.

OMEIZA, G. K.; KABIR, J.; KWAGA, J. K. P.; KWANASHIE, C. N.; MWANZA, M.; NGOMA, L. A risk assessment study of the occurrence and distribution of aflatoxigenic Aspergillus flavus and aflatoxin $\mathrm{B}_{1}$ in dairy cattle feeds in a central northern state, Nigeria. Toxicology Reports, v. 5, p. $846-856,2018$.

ONILUDE, A. A.; FAGADE, O. E.; BELLO, M. M.; FADAHUNSI, I. F. Inhibition of aflatoxin-producing aspergilli by lactic acid bactéria isolates from indigenously fermented cereal gruels. African Journal of Biotechnology, v. 4, p. 1404 - 1408, 2005.

PARK, D. L. Effect of processing on aflatoxin. In: Mycotoxins and Food Safety, 1 ed. New York: Kluwer Academic, v. 504, p. 173 - 179, 2002. 
PEI, S. C.; ZHANG, Y. Y.; EREMIN, S. A.; LEE, W. J. Detection of aflatoxin $\mathrm{M}_{1}$ in milk products from China by ELISA using monoclonal antibodies. Food Control, v. 20, p. 1080 1085, 2009.

PIERIDES, M.; EL-NEZAMI, H.; PELTONEN, K.; SALMINEN, S.; AHOKAS, J. Ability of dairy strains of lactic acid bactéria to bind aflatoxin $\mathrm{M}_{1}$ in a food model. Journal of Food Protection, v. 63, p. 645 - 650, 2000.

PITT, J. I.; TANIWAKI, M. H.; COLE, M. B. Mycotoxin production in major crops as influenced by growing, harvesting, storage and processing, with emphasis on the achievement of Food Safety Objectives. Food Control, v. 32, p. 205 - 215, 2013.

PRANDINI, A.; TANSINI, G.; SIGOLO, S.; FILIPPI, L.; LAPORTA, M.; PIVA, G. On the occurrence of aflatoxin $\mathrm{M}_{1}$ in milk and dairy products. Food and Chemical Toxicology, v. 47, p. $984-991,2009$.

SAKIN, F.; TEKELI, I. O.; YIPEL, M.; KUREKCI, C. Occurrence and health risk assessment of aflatoxins and ochratoxin A in Sürk, a Turkish dairy food, as studied by HPLC. Food Control, v. 90, p. $317-323,2018$.

SALAH-ABBÈS, J. B.; ABBÈS, S.; JEBALI, R.; HAOUS, Z.; OUESLATI, R. Potential preventive role of lactic acid bacteria against aflatoxin $\mathrm{M}_{1}$ immunotoxicity and genotoxicity in mice. Journal of Immunotoxicology, v. 12, p. 1 - 8, 2015.

SANTOS, M. C.; SOUSA, R. B.; OLIVEIRA, S. E. M.; LIMA, K. S. C.; LIMA, A. L. S. Micotoxinas e seu potencial como agentes de guerra. Revista Virtual de Química, v. 6, p. $761-778,2014$.

SARLAK, Z.; ROUHI, M.; MOHAMMADI, R.; KHAKSAR, R.; MORTAZAVIAN, A. M.; SOHRABVANDI, S.; GARAVAND, F. Probiotic biological strategies to decontaminate aflatoxin $\mathrm{M}_{1}$ in a traditional Iranian fermented milk drink (Doogh). Food Control, v. 71, p. $152-159,2017$.

SARTORI, A. V.; MATTOS, J. S.; MORAES, M. H. P.; NÓBREGA, A. W. Determination of aflatoxins $\mathrm{M}_{1}, \mathrm{M}_{2}, \mathrm{~B}_{1}, \mathrm{~B}_{2}, \mathrm{G}_{1}$ and $\mathrm{G}_{2}$ and ochratoxin $\mathrm{A}$ in UHT and powdered milk by modified QuEChERS method and ultra-high-performance liquid chromatography tandem mass spectrometry. Food Analytical Methods, v. 8, p. 2321 - 2330, 2015.

SASSAHARA, M.; NETTO, D. P.; YANAKA, E. K. Aflatoxin occurrence in foodstuff supplied to dairy cattle and aflatoxin $\mathrm{M}_{1}$ in raw milk in the North of Paraná state. Food and Chemical Toxicology, v. 43, p. $981-984,2005$.

SCAGLIONI, P. T.; BECKER-ALGERI, T.; DRUNKLER, D.; BADIALE-FURLONG, E. Aflatoxin $B_{1}$ and $M_{1}$ in milk. Analytica Chimia Acta, v. 829, p. 68 - 74, 2014.

SEDAGHAT, H.; ESKANDARI, M. H.; MOOSAVI-NASAB, M.; SHEKARFOROUSH, S. S. Application of non-starter lactic acid bacteria as biopreservative agents to control fungal spoilage of fresh cheese. International Dairy Journal, v. 56, p. 87 - 91, 2016.

SEVIM, S.; TOPAL, G. G.; TENGILIMOGLU-METIN, M. M.; SANCAK, B.; KIZIL, M. 
Effects of inulin and lactic acid bacteria strains on aflatoxin $\mathrm{M}_{1}$ detoxification in yogurt. Food Control, v. 100, p. 235 - 239, 2019.

SIBAJA, K. V. M.; GONÇALVES, K. D. M.; GARCIA, S. O.; FELTRIN, A. C. P.; NOGUEIRA, W. V.; BADIALE-FURLONG, E.; GARDA-BUFFON, J. Aflatoxin $\mathrm{M}_{1}$ and $\mathrm{B}_{1}$ in Colombian milk powder and estimated risk exposure. Food Additives \& Contaminants: Part B, v. 12, p. $1-8,2019$.

SOKOUTIFAR, R.; RAZAVILAR, V.; ANVAR, A. A.; SHOEIBY, S. Degraded aflatoxin $\mathrm{M}_{1}$ in artificially contaminated fermented milk using Lactobacillus acidophilus and Lactobacillus plantarum affected by some bio-physical factors. Journal of Food Safety, v. 38 , p. $1-12,2018$.

SOUZA, G. N.; CARVALHO, A. C.; MENDONÇA, L. C. Qualidade do leite. In: Manual de bovinocultura de leite. Juiz de Fora: Embrapa Gado de Leite; Brasília: LK Editora, p. 545, 2010.

SWEENEY, M. J.; DOBSON, A. D. W. Mycotoxin production by Aspergillus, Fusarium and Penicillium species. Internatinal Journal of Food Microbiology, v. 43, p. 141 -158, 1998.

TADESSE, S.; BERHANU, T.; WOLDEGIORGIS, A. Z. Aflatoxin $\mathrm{M}_{1}$ in milk and milk products marketed by local and industrial producers in Bishoftu town of Ethiopia. Food Control, v. 118, p. 1 - 10, 2020.

TAHEUR, F. B.; FEDHILA, K.; CHAIEB, K.; KOUIDHI, B.; BAKHROUF, A.; ABRUNHOSA, L. Adsorption of aflatoxin $\mathrm{B}_{1}$, zearalenone and ochratoxin $\mathrm{A}$ by microorganisms isoltaed from kefir grains. International Journal of Food Microbiology, v. 251, p. $1-7,2017$.

TOMASEVIC, I.; PETROVIC, J.; JOVETIC, M.; RAICEVIC, S.; MILOJEVIC, M.; MIOCINOVIC, J. Two year survey on the occurrence and seasonal variation of aflatoxin $\mathrm{M}_{1}$ in milk and milk products in Serbia. Food Control, v. 56, p. 64 - 70, 2015.

WOCHNER, K. F.; MOREIRA, M. C. C.; KALLSCHNE, D. L.; COLLA, E.; DRUNKLER, D. Detoxification of aflatoxin $\mathrm{B}_{1}$ and $\mathrm{M}_{1}$ by Lactobacillus acidophilus and prebiotics in whole cow's milk. Journal of Food Safety, v. 39, p. 1 - 10, 2019.

WORLD HEALTH ORGANIZATION - WHO. Aflatoxins: aflatoxins pose a serious health risk to humans and livestock. Suíça, n. 18.1, p. $1-5,2018$. Disponível em: https://www.who.int/foodsafety/FSDigest_Aflatoxins_EN.pdf. Acesso em: 01 agosto 2020.

WU, Q.; JEZKOVA, A.; YUAN, Z.; PAVLIKOVA, L.; DOHNAL, V.; KUCA, K. Biological degradation of aflatoxinas. Drug Metabolism Reviews, v. 41, p. 1- 7, 2009.

XIONG, J.; XIONG, L.; ZHOU, H.; LIU, Y.; WU, L. Occurrebce of aflatoxin B 1 in dairy cow feedstuff and aflatoxin $\mathrm{M}_{1}$ in UHT and pasteurized milk in central China. Food Control, v. 92, p. $386-390,2018$. 
KRAUS, R. B; SANTOS, P. R; DORS, G. C; NASCENTE, P. S; LUND, R. G.

XIONG, J.; PENG, L.; ZHOU, H.; LIN, B.; YAN, P.; WU, W.; LIU, Y.; WU, L.; QIU, Y. Prevalence of aflatoxin $\mathrm{M}_{1}$ in raw milk and three types of liquid milk products in centralsouth China. Food Control, v. 108, p. 2 - 5, 2020. 